\title{
STUDENT PERCEPTION OF AN ACTIVITY BASED ON ESCAPE ROOMS FOR LEARNING AT UNIVERSITY
}

\author{
Inmaculada Mateos-Aparicio ${ }^{1}$, Marta Sánchez-Paniagua ${ }^{2}$, Alejandra García-Alonso ${ }^{1}$, \\ Beatriz López-Ruiz ${ }^{2}$, Marina Molina ${ }^{3}$, María Moreno-Guzmán ${ }^{2}$, María Luisa Pérez- \\ Rodríguez, José Raggio ${ }^{4}$, Carmen Rueda ${ }^{2}$, Paz Sevilla $^{2}$, Cristina Bodas-Folguera ${ }^{1}$, \\ Rocío de la Peña-Armada ${ }^{1}$ \\ ${ }^{1}$ Departamento de Nutrición y Ciencia de los Alimentos, Facultad de Farmacia. Universidad \\ Complutense de Madrid (SPAIN) \\ ${ }^{2}$ Departamento de Química en Ciencias Farmacéuticas, Facultad de Farmacia. Universidad \\ Complutense de Madrid (SPAIN) \\ ${ }^{3}$ Departamento de Química Orgánica I, Facultad Óptica y Optometría. Universidad \\ Complutense de Madrid (SPAIN) \\ ${ }^{4}$ Departamento de Farmacología, Famacognosia y Botánica, Facultad de Farmacia. Universidad \\ Complutense de Madrid (SPAIN)
}

\begin{abstract}
The "escape rooms" are team games to "escape" from a room or a virtual room. This room is full of challenges that must be passed to win (escape) within a given time limit [1].

Due to the traditional teaching is causing problems around motivation and commitment and it is perceived as ineffective and boring by many students, the use of educational games is very promising because they are a teaching tool to enhance the non-cognitive skills such as problem solving, collaboration and communication. The games have a remarkable motivating power due to the use of a series of mechanisms that encourage people to participate in them, often without any reward, just for the satisfaction of playing and competing, and the possibility of winning [2].

In the academic course 2019-2020, we have developed activities based on "escape room" in different subjects: "Science and Analysis of water and beverages" of the Degree in Food Science and Technology, "Analytical Chemistry I" and "Pharmaceutical Physico-Chemistry" of the Pharmacy Degree and "Chemistry" of the Degree in Optics and Optometry at Complutense University, Madrid.

For the development of the project, all the characteristics and the progress of the different phases of the escape room seminar were informed in the first day of class and through the Virtual Campus platform. Students grouped themselves (5-7 people/group) and appointed a spokesperson that was responsible to reply the puzzles of the activity. At the end of this action, the students voluntarily responded to Likert surveys to assess their implication and their perception about their learning, teamwork, and whether if they enjoyed with the proposed activity. They replied with a high score (4/5) to questions such as "It was useful to improve the subject understanding" and "It was useful to establish basic concepts". Furthermore, they assigned the highest score (5/5) when replied about "It was a good option as a class activity" and "I liked participate in the
\end{abstract}


activity". Thus, the "escape room" activity resulted in an effective tool for the student motivation and improved their commitment to the subject.

Keywords: Gamification, Escape room, Higher Education, Innovation

\section{INTRODUCTION}

The teaching concept at the University level in countries belonging to the European Higher Education Area should be starting to show a step by step switch from traditional master classes to novel educational methodologies devoted to obtain a better student's involvement during the learning process [3]. Our current way of living uses massively new technologies as tools to develop fast and efficient communication skills, and this fact cannot be ignored by the University that has the responsibility of being always open and permeable to changes in society. These new technologies open a big amount of possibilities for teachers in order to improve their educational skills, because they are available to almost everyone nowadays, many of them are cheap, they proportion fast evaluation outputs, and they break a likely existing gap between teachers and students due to generational differences. These new technologies are perfect tools to be used in gamification designs, one important alternative available when new teaching strategies are attempted, that is showing measurable positive results in relation with obtaining better students' involvement and improved academic results $[2,4,5]$. The concept promotes active learning, student's participation, obtains good results in assimilating theoretical concepts and, at the same time, allows working non-cognitive skills such as work team, problems-solving, decision-making and communication abilities [6]. Besides, the use of popular sources of entertainment in gamification strategies such as escape-rooms, have shown successful results in the recent years [6,7]. The final objective of this proposal is being able of leaving the classroom after having shown competitive knowledge related with the particular subject being addressed and several types of noncognitive skills. Students compete against the rest of the class and against time as well, meaning that they do not only have to show that they have acquired a particular concept, but that they also have to show how to use it properly in order to win. A former paper explained how our teaching research group applied and developed different escape-rooms proposals at different subjects of several Degrees at Complutense University, Madrid [6]. Here, we aim to show the tools used to let students evaluate the project and the results coming from this evaluation. Given that students' opinion evaluation is an essential tool in order to try to go beyond traditional teaching methodologies [8], the output and the consequences of this type of evaluation are of big relevance if a continuous improvement of teaching methodologies is aimed.

\section{MATERIAL AND METHODS}

We briefly describe the main objectives of the project in order to detail the methodology developed to obtain an adequate evaluation by the students [6]:

1. To remove from students' minds the idea of being passive receptors in the teaching-learning procedure

2. To encourage teamwork among students, which have to choose a team between their class-mates in order to be competitive through the activity proposed. This objective is linked to several relevant transversal competences such as development of self-organization, planning and execution abilities, together with the development of skills related with the ability of problems solving at different situations (individually or working in team)

3. To foster the ability of applying theoretical concepts to solve real situations

4. To promote students participation and degree of involvement by stimulating other relevant competencies such as oral communication skills and creativity

In order to be able of evaluating this main objectives, we have used different indicators, all linked at different extents with student's perception, as follows (i) \% of students participating in the proposal made by the teacher at different subjects, considered as an indirect indicator because the higher the participation at each subject the higher the interest shown by the students; (ii) students responses to several questionnaires / surveys proposed by the teachers. This second indicator is a direct output made by the student and is a powerful in order to identify strong and weak points of our proposal and provides opportunities to selfevaluation and improvement of our work. The questionnaires / surveys mentioned have been designed with 
Google Forms, so that they could be answered online (the link to access was provided in the Virtual Campus). The questionnaires consisted of 9 items, with a Likert-type scale of 5 points, where 1 was "strongly disagree" and 5 "strongly agree".

Objective 1 was evaluated using indirect (participation) and direct (student's opinion) indicators as already explained, while the four other were mainly evaluated following the direct outputs provided by students through the LIKERT surveys.

The subjects and Degrees (all belonging to Complutense University, Madrid) where the project development was evaluated are: Degree of Food Science and Technology, with the subject involved being "Science and Analysis of water and beverages"; Degree of Pharmacy, with the subjects involved being "Analytic Chemistry I" and "Pharmaceutical Physico-Chemistry"; Degree of Optics and Optometry, with the subject "Chemistry".

The general lockout consequence the Covid-19 crisis in March 2020 derived to a switch in the development and in the evaluation of the activity to an online alternative.

\section{RESULTS}

Objective 1. To remove from students' minds the idea of being passive receptors in the teaching-learning process.

Indicator 1.1. Student's participation in the activity at each of the subjects involved in the project

- Analytic Chemistry: 73.4-100\% (depending on group)

- Pharmaceutical Physico-Chemistry: 96\%

- Chemistry: $21 \%$

- Science and Analysis of water and beverages: 93\%

With the exception of the subject of Chemistry, student's involvement in the activity was massive, highlighting a big degree of interest to the proposal made.

Indicator 1.2. General assessment of the activity in the Likert survey: Items like "The proposal is a good option as a seminar" (with a mean of $4.4 \pm 0.8$ ), "I would like to see proposals as this one included in all subjects" (4.3 \pm 0.9$)$ and "I enjoyed participating in this proposal" $(4.5 \pm 0.7)$ obtained a statistical mode of 5 over 5 (see Fig. 1)

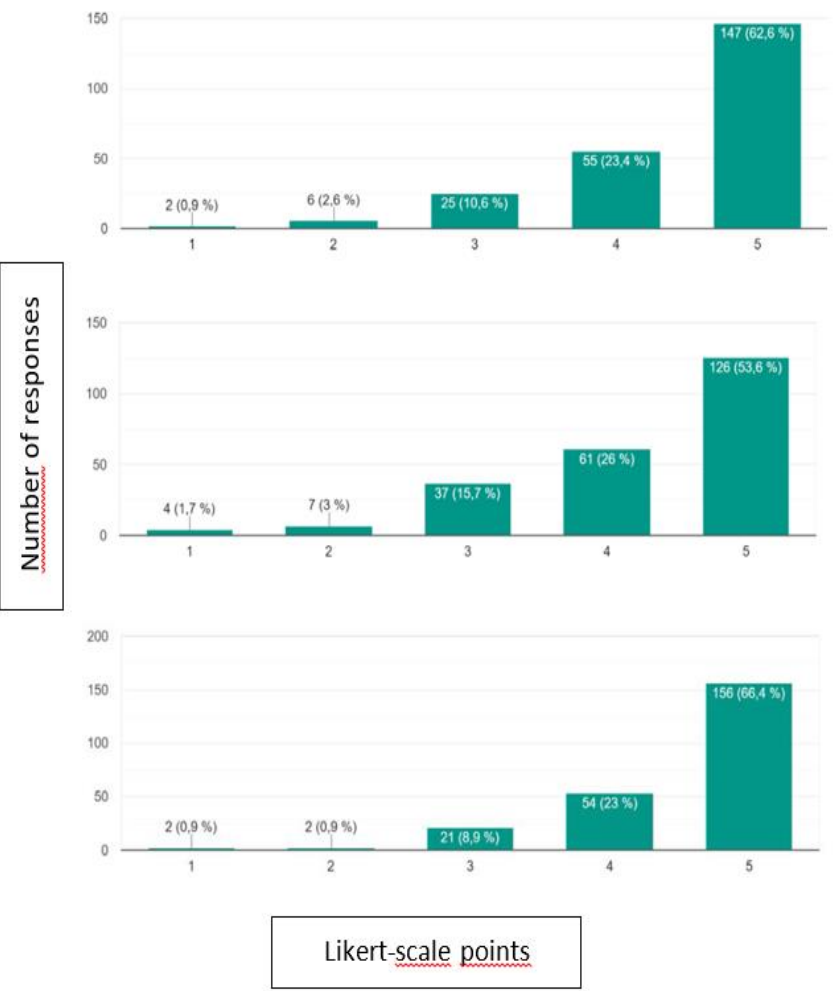


Fig. 1. Representation of student's responses in Likert surveys to indicators linked to objective 1. In sequential order, up to down, responses to items: "The proposal is a good option as a seminar", "I would like to see proposals as this one included in all subjects", "I enjoyed participating in this proposal". Number of students participating to each question $=235$

Objective 2. To encourage work team among students, which have to choose a team between their classmates in order to be competitive through the activity proposed. This objective is linked to several relevant transversal competences such as development of self-organization, planning and execution abilities, together with the development of skills related with the ability of problems solving at different situations (individually or working in team).

The importance of working together making groups was transferred to students, and they made their own choices about this point. A spokesperson was chosen to transmit the agreed opinion of the whole group at each situation, meaning that they worked making frequent deals among them

Indicator 2.1. Students' opinion in relation with working in groups provided by the Likert survey. The item "I have improved my capacity of working together with other students" obtained a mean of $3,9 \pm 0.9$ and a statistical mode of $4 / 5$ (Fig. 2).
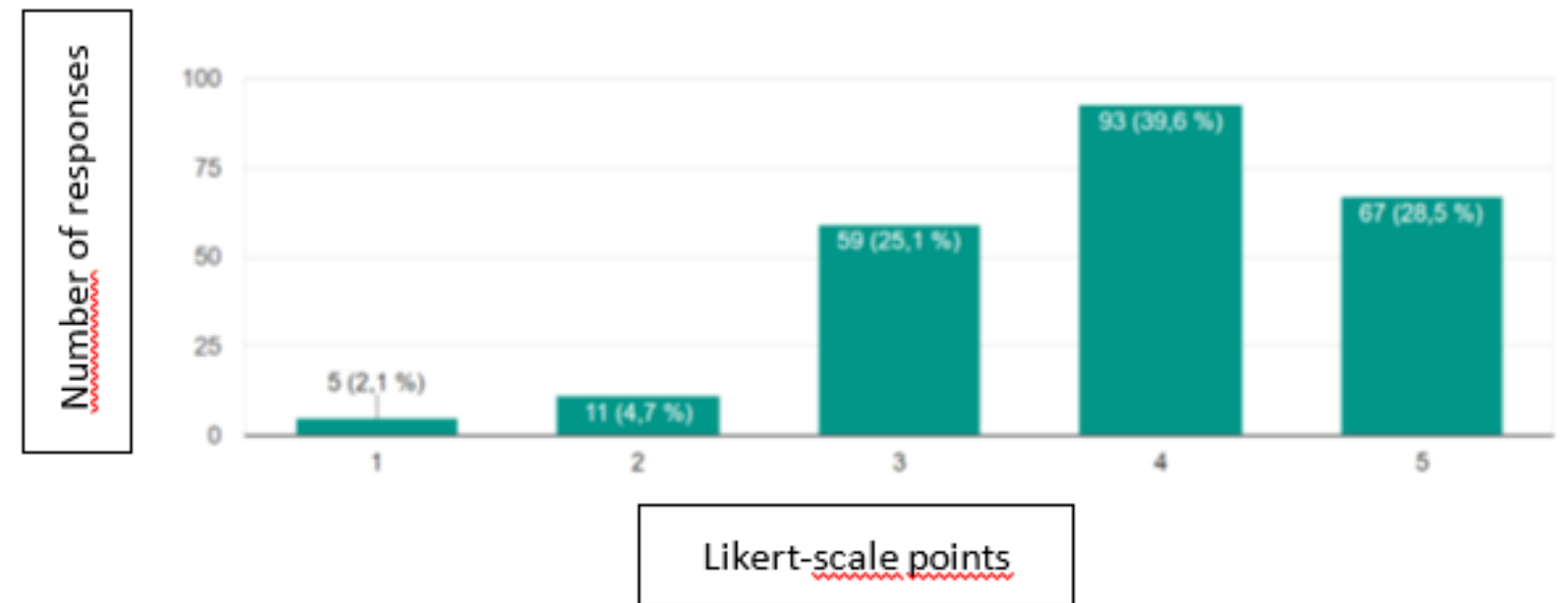

Fig. 2. Representation of student's responses in Likert surveys to indicators linked to objective 2. Responses to item: "I have improved my capacity of working together with other students". Number of students participating to each question $=235$

Objective 3. To foster the ability of applying theoretical concepts to solve real situations.

In order to evaluate this objective, the following items were proposed in the Likert surveys: "The activity has been useful to me in order to a better understanding of the subject" (mean value of $3.5 \pm 1.0$ ), "The activity has been useful to me in order to assimilate basic concepts of the subject" $(3.9 \pm 1.0)$ and "I agree with using

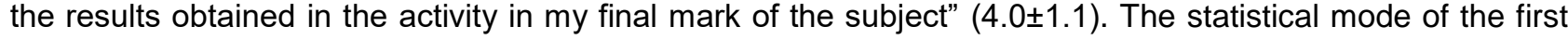
two items was $4 / 5$ and for the third one it was $5 / 5$ (Fig. 3 ) 


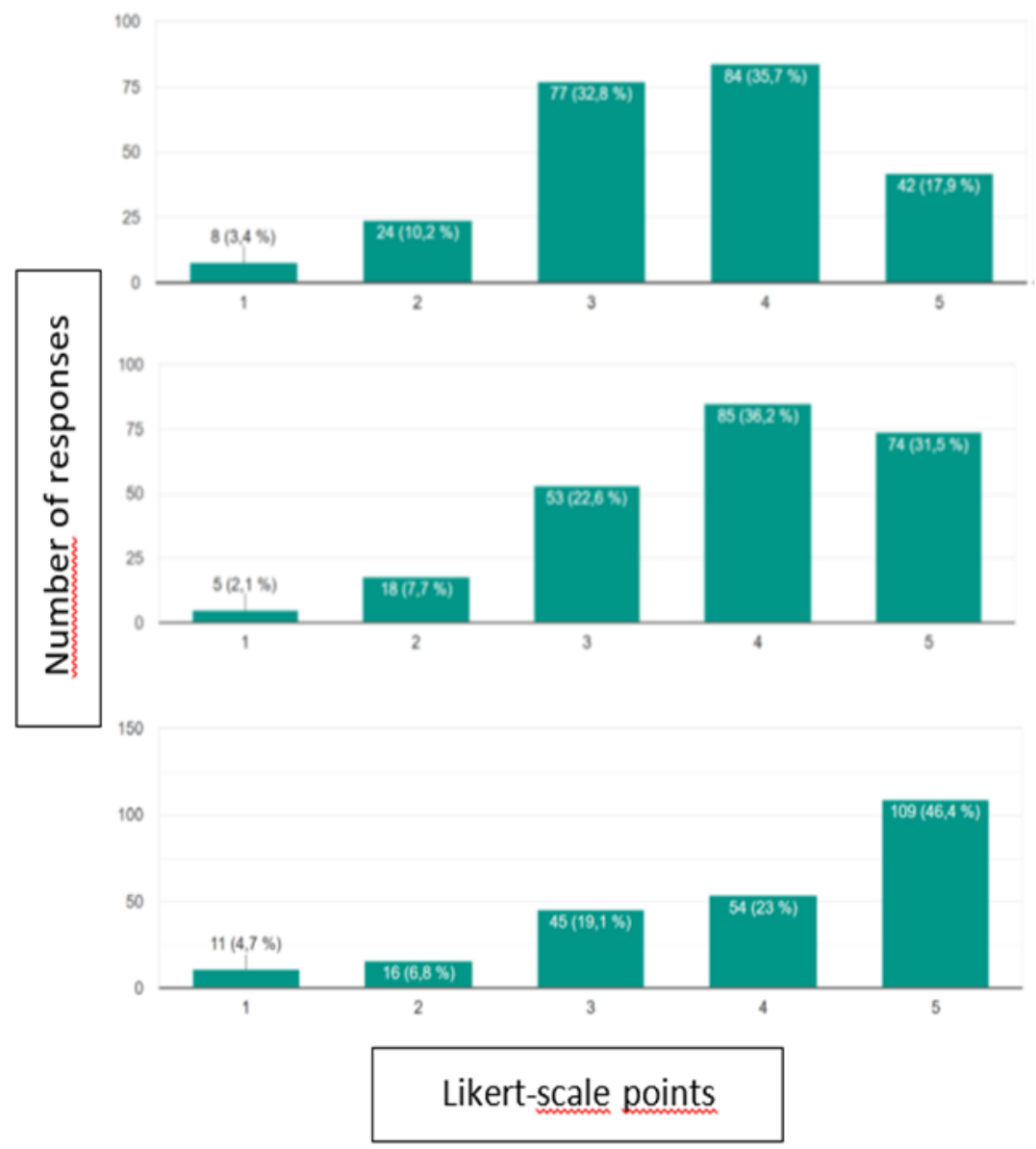

Fig. 3. Representation of student's responses in Likert surveys to indicators linked to objective 3 . In sequential order, up to down, responses to items: "The activity has been useful to me in order to a better understanding of the subject", "The activity has been useful to me in order to assimilate basic concepts of the subject", "I agree with using the results obtained in the activity in my final mark of the subject". Number of students participating to each question $=235$

Objective 4. To promote students participation and degree of involvement by stimulating other relevant competencies such as oral communication skills and creativity

Several items evaluated in the Likert surveys where linked at different extents to non-cognitive skills such as being able of working together, communication abilities, raising interest in learning, ability to apply knowledge, etc. Examples of this items -already mentioned and plotted at different objectives-are: "I have improved my capacity of working together with other students" obtained a mean of $3.9 \pm 0.9$ and a statistical mode of $4 / 5$; "The proposal is a good option as a seminar" (with a mean of $4.4 \pm 0.8$ ), "I would like to see proposals as this one included in all subjects" $(4.3 \pm 0.9)$ and "I enjoyed participating in this proposal" $(4.5 \pm 0.7)$ obtained a statistical mode of 5 over 5 .

\section{CONCLUSIONS}

The general perception is that the evaluation made by the students using the Likert surveys is very positive, indicating that using gamification procedures in general, and escape-rooms for our particular case, are strongly useful enhancing active learning. The former results of our research group [4,5,6], together with high marks of some items obtained in the Likert surveys such as "I found it original" $(5.0 \pm 0.0)$, "I enjoyed participating in this proposal" $(4,9 \pm 0.3)$ and "I found it a good seminar option" $(4.7 \pm 0.4)$ encourage us to continue through this successful research line in teaching innovation.

\section{ACKNOWLEDGEMENTS}

The authors want to thank the financial support of the Project "Innova-Docencia" $n^{\circ} 118$ entitled "Escape Seminar" from Universidad Complutense de Madrid. 


\section{REFERENCE LIST}

[1] Wiemker M, Elumir E, \& Clare A (2015). Escape Room Games: "Can you transform an unpleasant situation into a pleasant one?"

[2] Dicheva D, Dichev C, Agre G, \& Angelova G (2015). Gamification in Education: A Systematic Mapping Study. Educational Technology \& Society, 18 (3).A. Einstein, "General theory of relativity," Annalen der Physik, vol. 49, no. 7, pp. 769-822, 1916.

[3] The European Higher Education Area (EHEA). https://www.study.eu/article/the-european-highereducation-area-ehea.

[4] Mateos-Aparicio I et al. (2016). "Trivial pursuit" board game as a tool to stimulate the students participation in class. Proceedings 9th International Conference of Education, Research and Innovation, 3995-4000

[5] Mateos-Aparicio I, et al. (2017). Gamification of learning through a version of the "Trivial pursuit" board game. Proceedings 10th International Conference of Education, Research and Innovation, 727-733

[6] Mateos-Aparicio I, et al. (2019). Escape Seminar: Adapting Escape Rooms for Learning At University. Proceedings of INTED 2020 Conference $2^{\text {nd }}-4^{\text {th }}$ March 2020, Valencia, Spain, 930-934.

[7] Wiemker M, Elumir E, \& Clare A (2015). Escape Room Games: "Can you transform an unpleasant situation into a pleasant one?"

[8] Bain, Kevin (2004), What the Best College Teachers Do?, Cambridge/Londres, Harvard University Press. 